\title{
PERAWATAN LUKA PENDERITA KUSTA DENGAN DAUN TETANUS (LEEA AEQUATA L) PENGOBATAN TRADISONAL SUKU KARO
}

DOI: https://doi.org/10.33024/jkpm.v4i5.4212

\author{
Seri Rayani Bangun ${ }^{1 *}$, Mestiana Br Karo ${ }^{2}$, Barce Inel Crevis Gulo ${ }^{3}$, \\ Anna Pefrianti Siburian ${ }^{4}$, Fransiskanes Manurung ${ }^{5}$, Lisbeth L, Sihotang ${ }^{6}$ \\ ${ }^{1-6}$ STIKes Santa Elisabeth Medan
}

Disubmit: 16 April 2021

Diterima: 04 Juni 2021

Diterbitkan: 01 Oktober 2021

Email: serirayani2009@gmail.com

\begin{abstract}
ABSTRAK
Kusta merupakan penyakit yang disebabkan oleh mycobacterium leprae. Penyakit kusta pada stadium lanjut sering disertai luka akibat terjadinya kerusakan saraf pada daerah kaki yang menimbulkan gangguan sensibilitas kelumpuhan otot dan luka penderita kusta sering infeksi dan sulit untuk disembuhkan karena pasien sering terlambat datang untuk berobat. Perawatan luka kusta dengan menggunakan agen topikal yang tepat merupakan faktor terpenting dalam penyembuhan Luka penderita Kusta. Tujuan dilakukannya penelitian ini diharapkan dapat meningkatkan pengetahuan masyarakat terhadap pentingnya perawatan luka pada penderita kusta di pusat Rehabilitasi kusta Desa Galang. Adapun kegiatan yang dilakukan yaitu berupa pemeriksaan kesehatan dan juga perawatan luka penderita kusta dengan menggunakan obat tradisional tambar tetanus (LEEA AEQUATA L). Penderita kusta yang mengikuti perawatan luka sebanyak 34 orang. Masyarakat sangat antusias dalam mengikuti perawatan luka yang dilaksanakan serta akan berupaya melaksanakannya secara mandiri dirumah untuk meningkatkan status kesehatan penderita kusta.
\end{abstract}

Kata Kunci : Penderita Kusta, Luka, LEEA AEQUATA L.

\section{ABSTRACT}

Leprosy is a disease caused by mycobacterium leprae. Leprosy at an advanced stage is often accompanied by injuries due to nerve damage in the leg area which causes impaired sensibility, muscle paralysis, and leprosy wounds are often infected and difficult to heal because patients often come late for treatment. The treatment of leprosy wounds by using the right topical agent is the most important factor in the healing of leprosy wounds. The purpose of this research is expected to increase public knowledge of the importance of wound care for people with leprosy at the Leprosy Rehabilitation Center in Galang Village. The activities carried out are in the form of health checks and also the treatment of leprosy wounds using the traditional tambar tetanus medicine(LEEA AEQUATA $L)$. The community is very enthusiastic in participating in the counseling that is carried out and will try to implement it independently which can improve the health status of leprosy sufferers.

Keywords: Leprosy Patients, Wounds, LEEA AEQUATA L. 


\section{PENDAHULUAN}

Penyakit kusta disebabkan oleh micobakterium leprae, jenis kuman aerob tidak membentuk spora bersifat tahan asam yang dapat menyebar kemanusia melalui kontak langsung dengan penderita yang sama sama mempunyai lesi baik mikroskopis dan makroskopis serta kontak yang berulang. Kuman ini mengalami proses perkembangbiakan selama 2-3 minggu dengan masa inkubasi 2- 5 tahun (Malinda, 2015)

Penyakit kusta pada umumnya merupakan penyakit yang menakutkan bagi masyarakt karena jaman dahulu penyakit kusta dianggap hukuman dari Tuhan, sehingga penderitanya sering mengalami gangguan sosial karena adanya gangguan pada kulit sampai adanya pelepasan bagian tubuh.

Pengobatan kepada penderita kusta adalah merupakan salah satu cara pemutusan mata rantai penularan. Kuman kusta diluar tubuh manusia dapat hidup 24-48 jam dan ada yang berpendapat sampai 7-9 hari, ini tergantung dari suhu dan cuaca diluar tubuh manusia tersebut. Makin panas cuaca makin cepatlah kuman kusta mati. Jadi dalam hal ini pentingnya sinar matahari masuk ke dalam rumah dan hindarkan terjadinya tempat-tempat yang lembab (Novita, 2019).

Kegagalan pengobatan karena adanya stigma yang melekat bahwa penyakit kusta sering dilakukan diskriminatif, kurang kesempatan mendapatkan lowongan kerja, kurang diterima masyarakat lain. Penyakit kusta memiliki beban tinggi atau disebut dengan triple burden disease karena penyakit kusta merupakan penyakit yang belum tuntas saat ini, penyakit menular yang lama timbul kembali dan merupakan penyakit menular dimasyarakat.

Penemuan penderita kusta sering terlambat serta karakteristik penanganan penderita kusta di wilayah masyarakat cukup bervariasi seperti masih adanya kondisi lesi yang memburuk, kondisi kecacatan klien kusta, adanya stigma sosial masyarakat terhadap pasien kusta, manajemen pengobatan yang sering terputus dan jangkauan pelayanan secara rutin masih kurang (Siregar, 2019)

Selama periode 2008 sampai dengan 2013, angka penemuan baru kusta pada tahun 2013 adalah angka yang terendah yaitu sebesar 6.79 per 100.000 penduduk. Sedangkan angka prevalensi berkisar antara 0.79 hingga 0.96 per 10.000 (7.9 sampai 9.6 per 100.000 penduduk) dan telah mencapai target $<1$ per 10.000 penduduk atau < 10 per 100.000 penduduk) Profil kesehatan postdarin 2013.

Penyakit kusta pada stadium lanjut sering disertai luka akibat terjadinya kerusakan saraf pada daerah kaki yang menimbulkan gangguan sensibilitas kelumpuhan otot, kult kering akibat hilangnya fungsi kelenjar keringat dan lemak. Luka pada penderita kusta sering sulit untuk disembuhkan karena pasien sering terlambat datang untuk berobat. Luka pada penderita kusta sering terjadi infeksi. Penyakit infeksi merupakan salah satu masalah dalam bidang kesehatan yang dapat disebabkan oleh bakteri ataupun jamur. Senyawa flavonoid, saponin dan steroid/triterpenoid merupakan senyawa kimia yang memiliki potensi sebagai antibakteri dan antivirus. Penyebab infeksi lain pada luka dapat juga disebabkan oleh bakteri Staphylococcus aureus, Staphylococcus epidermidis dan Pseudomonas aeruginosa. Luka yang sering terjadi pada penderita kusta adalah luka lepromatosa, luka stasis, luka plantar dan luka lainnya. Perawatan luka digunakan dengan prinsip perawatan luka secara teratur dengan cara membersihkan luka, melunakkan luka kemudian menggunakan topical. Perawatan luka kusta dengan menggunakan agen topical yang tepat merupakan factor penting dalam penyembuhan luka. Tambar tetanus telah dilaporkan 
efektif dalam penanganan penderita terkena tetanus namun untuk perawatan luka belum ada yang publikasi namun sangat sering dipergunakan oleh masyarakat terutama yang tinggal didaerah pedesaan sehingga penulis tertarik untuk melakukan penelitian perawatan luka dengan menggunakan obat tetanus ramuan suku karo (Hartanti, 2015).

\section{MASALAH}

Berdasarkan analisa situasi di atas maka dapatlah disimpulkan Penyakit kusta disebabkan oleh micobakterium leprae, Penyakit kusta pada stadium lanjut sering disertai luka akibat terjadinya kerusakan saraf pada daerah kaki yang menimbulkan gangguan sensibilitas kelumpuhan otot, kult kering akibat hilangnya fungsi kelenjar keringat dan lemak, pada penderita kusta di Desa Galang. Pusat Rehablitasi Gema Kasih Galang (Rehablitasi Kusta) merupakan daerah binaan STIKes Santa Elisabeth Medan sehingga penderita kusta ini dijadikan sebagai wadah Pengabdian kepada Masyarakat.

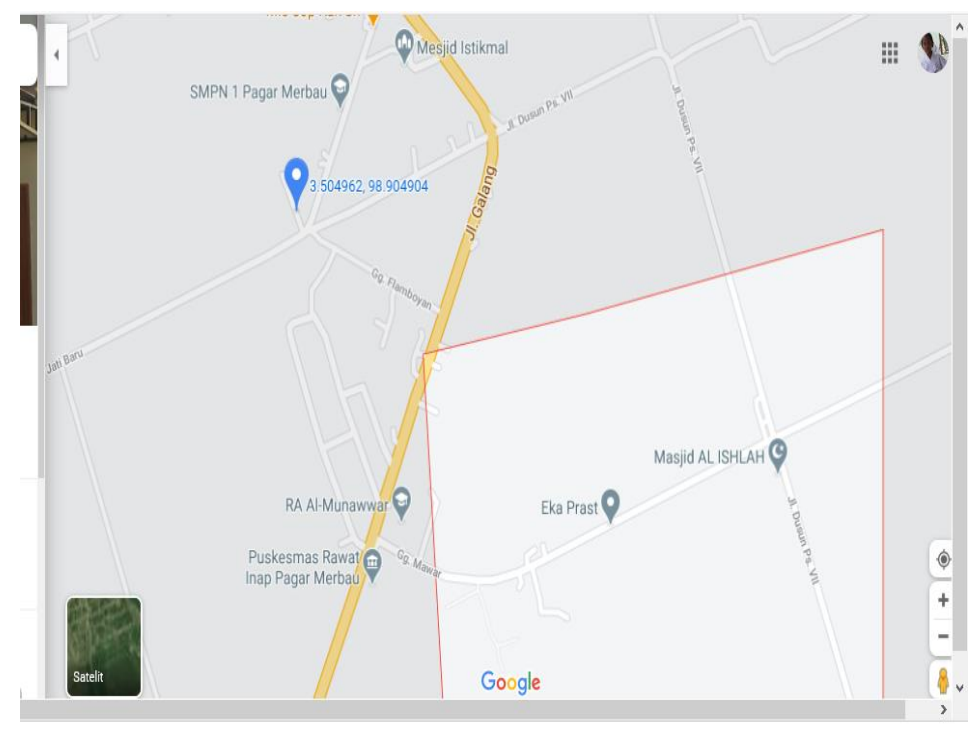

Gambar 2.1 Denah Lokasi

\section{METODE}

a. Solusi Yang ditawarkan

Berdasarkan prioritas permasalahan di bidang kesehatan yang telah disepakati bersama dengan warga di desa galang yang menderita kusta untuk membantu proses perawatan luka. Maka solusi yang ditawarkan untuk mengatasi permasalahan tersebut adalah melaksanakan kegiatan pelaksanaan perawatan luka secara teratur dengan menggunakan penderita kusta dengan menggunakan obat tradisonal tambar tetanus di desa galang.

b. Tahap pelaksanaan

\section{Langkah-langkah kegiatan}

Perawatan luka penderita kusta dengan menggunakan obat tradisional tambar tetanus, 
Perawatan tangan yang luka

1. Perhatian

a) Kurangi tekanan pada bagian yang luka dengan istirahat

b) Luka harus selalu bersih

c) Bila luka berbau, terasa panas dan bengkak segeralah ke puskesmas

2. Rendam

Rendam tangan yang luka 2 kali sehari dengan air bersih yang tidak panas selama 30 menit kemudian rendam luka dengan obat tetanus

3. Gosok

Setelah direndam, gosok kulit dengan menggunakan kassa yang sudah dibasahi dengan obat tetanus

4. Balut

Setelah tangan dibersihkan rendam kassa dengan obat tetanus, balutlah luka dengan kasa bersih supaya luka tidak mudah kotor

5. Istirahatkan tangan yang luka, jangan gunakan tangan untuk bekerja

Perawatan kaki yang luka

1. Perhatian

a) Kulit telapak kaki menjadi pecah-pecah

b) Luka pada telapak kaki karena: berjalan jauh berdiri lama terkena benda keras, tajam atau panas

\section{Periksa}

Periksalah telapak kaki setiap hari, bila ada kemerahan atau melepuh dan luka

3. Rendam kaki paling sedikit 1 kali sehari dengan air bersih (tidak panas), selama 30 menit kemudian rendam selama 15 menit dengan obat tetanus

4. Gosok

Setelah direndam, gosok kulit yang menebal dengan kassa yang dibasahi dengan obat tetanus

6. Balut

Setelah kaki dibersihkan rendam kassa dengan obat tetanus, balutlah luka dengan kasa bersih supaya luka tidak mudah kotor

5. Cegah

Gunakan selalu alas kaki untuk mencegah luka, pakai sepatu atau sandal dengan bagian dalam yang lembut.

\section{HASIL DAN PEMBAHASAN}

Kegiatan Pelaksanaan pemeriksaan kesehatan dan perawatan luka penderita kusta telah dilaksanakan bulan Mei sampai dengan Juni 2019 bertempat Di Pusat Rehablitasi Gema Kasih Galang (Rehablitasi Kusta) Kecamatan Galang Kabupaten Deli Serdang. Sebelum dilaksanakan Kegiatan penyuluhan Di Pusat Rehabilitas terlebih dahulu mereka melakukan pemeriksaan kesehatan sebelum melakukan perawatan luka. Pada saat kegiatan berlangsung diberikan kesempatan kepada penderita untuk memberikan pertanyaan mengenai penyakit yang diderita.

Kegiatan Pelaksanaan penyuluhan kesehatan Di Pusat Rehablitasi Gema Kasih Galang (Rehablitasi Kusta) Kecamatan Galang Kabupaten Deli Serdang sudah terlaksana dan para penderita kusta dalam menerapkan solusi yang ditawarkan merasa senang ketika tim pengusul yaitu dosen dan mahasiswa melakukan Kegiatan Pelaksanaan penyuluhan kesehatan di pusat rehabilitas, penderita kusta serta tim pengusul berharap kegiatan ini dapat terus berjalan dan rutin dilakukan agar kesehatan pasien penderita kusta dapat lebih baik lagi. 
Berikut adalah gambar Pelaksanaan kegiatan :
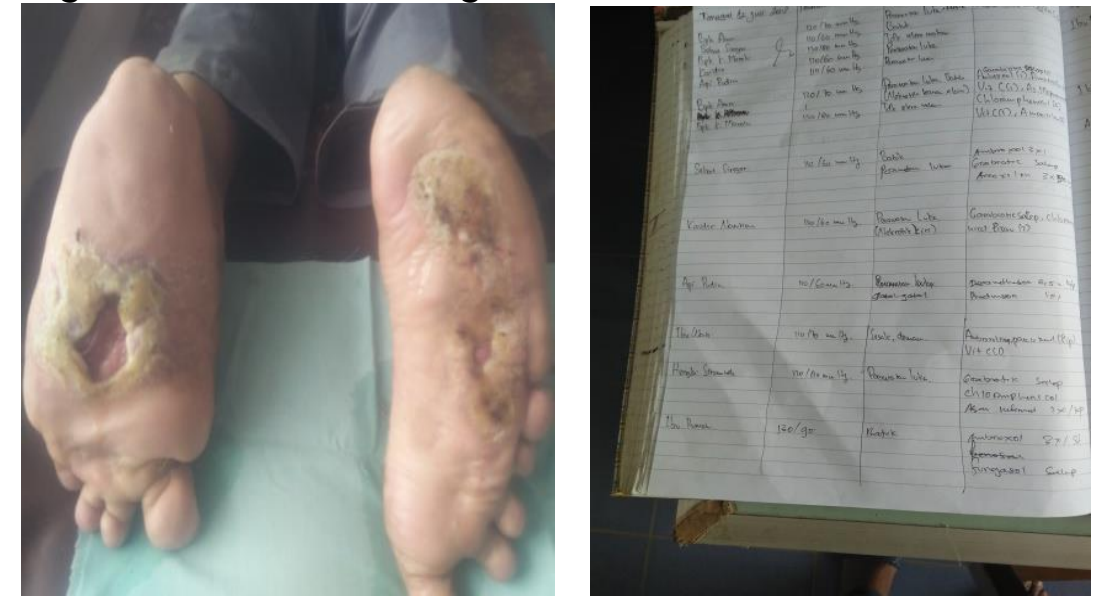

Gambar 4.1 . Pre-Intervasi
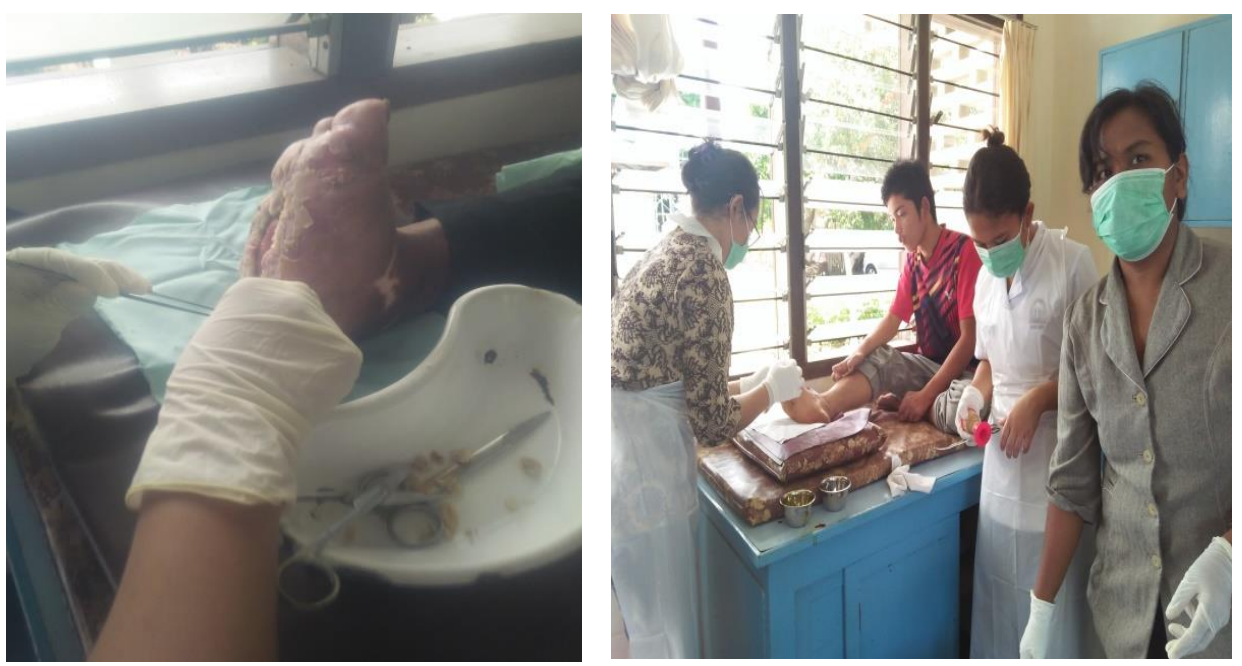

Gambar 4.2 . Pemeriksaan dan Tindakan
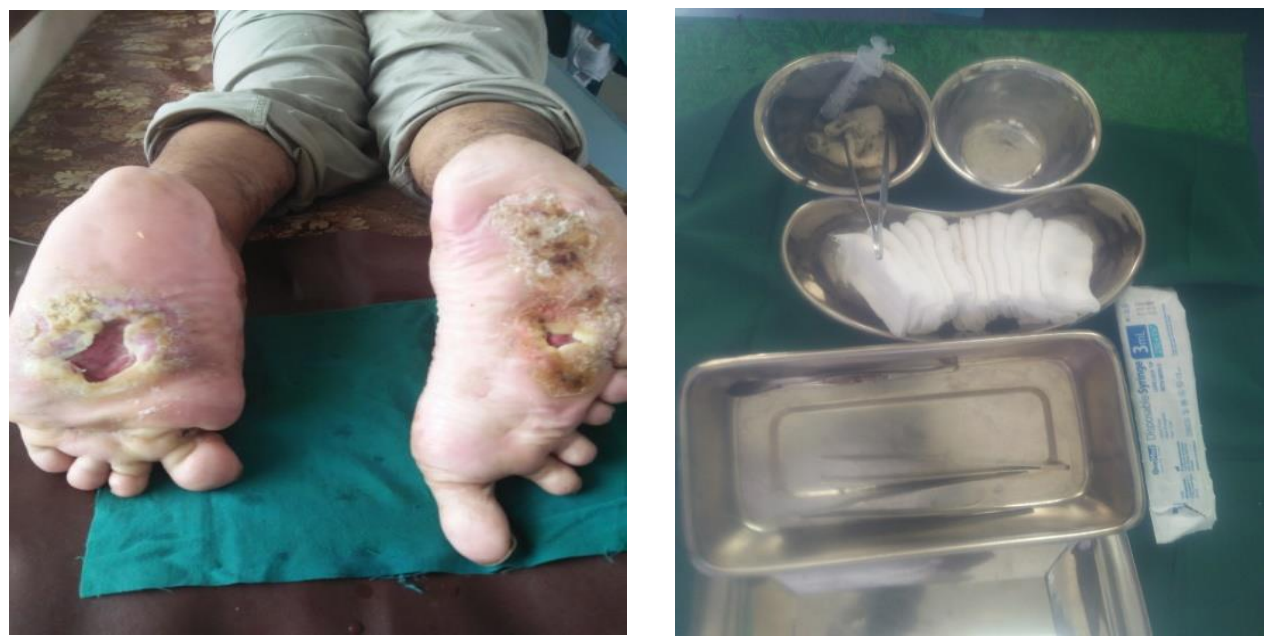

Gambar 4.3 Post Intervensi 


\section{KESIMPULAN}

1. Kegiatan pemeriksaan kesehatan dan perawatan luka penderita kusta Di Pusat Rehablitasi Gema Kasih Galang (Rehablitasi Kusta) Kecamatan Galang Kabupaten Deli Serdang

2. Kegiatan pemeriksaan kesehatan dan perawatan luka penderita kusta berjalan dengan lancar dan antusias dalam mengikuti penyuluhan yang dilaksanakan serta akan berupaya melaksanakannya secara mandiri di rumah.

\section{DAFTAR PUSTAKA}

Depkes RI. (2001). Inventaris Tanaman Obat Indonesia. Jilid II. Jakarta: Departemen Kesehatan dan Kesejahteraan Sosial RI Badan Penelitian dan Pengembangan Kesehatan. Halaman 195.

Fatmawati, A., Sudiyanto, H., \& Firdaus, M.N. (2020). Upaya Peningkatan Pengetahuan Masyarakat Tentang Pertolongan Pertama Pada Luka Bakar Melalui Pendekatan Focus Group Discussion Di Kelompok Dasa Wisma Perumahan Graha Majapahit Kabupaten Mojokerto. Jurnal Pengabdian Kepada Masyarakat, Vol.3 No.2, 430 - 436

Hartanti, R.D., Listyorini, L., \& Karima, M. (2015). Perawatan Diri Pasien Kusta. Jurnal Ilmiah Kesehatan. Vol VII No.1

Khare, C.P. (2007). Indian Medicinal Plants. New Delhi: Springer Science + Business Media, LCC. Halaman 366.

Malinda I. (2015). Skrining Fitokimia dan Uji Aktivitas Antibakteri Ekstrak Etanol Daun Tetanus ( Leea aequata L.) Pengobatan Tradisional Karo. Skripsi. Medan: Universitas Sumatera Utara

Mulyadi, A., Sepdianto, T.C., \& Mitayasari, E. (2017). Upaya Penderita Kusta Dalam Mencegah Peningkatan Derajat Kecacatan. Jurnal Ners dan Kebidanan. Vol. 4 No.3, 186-191

Novita, A. I. (2019). Buku Saku Penanganan Pasien Kusta. Unit Rehabilitasi Kusta RSUD Kelet

Rahman, M.A., Imran T. B., dan Islam, S. (2012). Antioxidative, Antimicrobial and Cytotoxic Effects Of The Phenolics Of Leea indica Leaf Extract. Saudi Journal of Biological Sciences. 20(2): 222

Siregar, T \& Ratnawati, D. (2019). Pendampingan Keluarga dan Kader Terhadap Penderita Kusta dalam Mencegah Kecacatan di Kelurahan Limo Kota Depok Jawa Barat. Jurnal Bakti Masyarakat Indonesia. Vol.2 No.2, 229236 